\title{
Participatory Natural Resource Management in Rural China: Making and Unmaking Environmental Narratives
}

\author{
Ju-Han Zoe Wang* ${ }^{1}$, Robert Fisher ${ }^{2,3}$ John Connell $^{2}$ \\ 1. Asia Institute, University of Melbourne. \\ 2. School of Geosciences, University of Sydney. \\ 3. Tropical Forests and People Research Centre, University of Sunshine Coast.
}

*Corresponding author:

Asia Institute, Sidney Myer Asia Centre, The University of Melbourne, Victoria 3010 Australia

Email: zoe.wang@unimelb.edu.au

\section{INTRODUCTION}

Community-based natural resource management (CBNRM) has become a popular and influential approach in shaping social relations and environmental practices concerning natural resource issues in rural China. Globally, CBNRM has been widely adopted since the 1980s, largely due to the failure of state and private power to deliver good outcomes in natural resource management (Dressler et al. 2010). The aim of this paper is to analyze the ways various environmental narratives are constructed through environmental NGO projects in rural China, and to discuss their implications. Case studies are drawn from participatory

This is the author manuscript accepted for publication and has undergone full peer review but has not been through the copyediting, typesetting, pagination and proofreading process, which may lead to differences between this version and the Version of Record. Please cite this article as doi: 10.1111/apv.12210

This article is protected by copyright. All rights reserved. 
NRM projects in Yunnan, where natural resources have been the arena for contest between various actors, including NGOs, local communities and the government.

CBNRM is based on the assumptions that local communities have the greatest interest in managing their resources, are more knowledgeable about their environment, and are capable of effective management due to their customary institutions of resource management (Tsing et al. 2001). CBNRM reverses 'top-down, center-driven conservation by focusing on the people who bear the cost of conservation' (Western and Wright 1994:7). It has become an orthodoxy for international donors and consequently affects the ways agencies, including environmental NGOs, implement their projects locally, and was introduced to China by international donors in the 1990s. The legitimacy of the CBNRM approach is often sustained by particular narratives framing the relationship between local communities and their environment. Within this framing, notions of indigeneity, traditional knowledge, customary law, and common resources are all related to constructing narratives suitable to support the CBNRM approach.

In China, environmental and development discourses can be categorized into three narrative themes, framing human-nature relationships: peasant, indigenous and community (Hathaway 2013). The peasant narrative, mainstreamed during the 1980s, perceived agricultural practices, such as slash and burn, as responsible for ecological destruction, and was espoused by Chinese scientists and officials and shared with international eNGOs (Hathaway 2013). Nowadays the Chinese government persists with the peasant narrative, evident in such environmental policies as ecological resettlement. The indigenous narrative sees indigenous peoples, with local knowledge and land rights, as generally practicing environmentally sound 
livelihood activities. This narrative was influenced by the global indigenous movement but reshaped locally by Chinese experts (Hathaway 2010). The community narrative, as part of an international shift to community-based efforts in conservation and development around the 1990s, saw local people as having knowledge and experience that made them valuable partners for development experts. Indigenous and community narratives have been widely adopted by eNGOs in China in support of CBNRM projects.

This paper explores how the CBNRM approach has been variously modified and practiced in rural China. Critical analysis of the role of narratives in framing society-environment interactions in China has attracted initial interest, with literature focused on how Chinese environmentalism is influenced by global environment and development discourses (Hathaway 2013; Litzinger 2004; Williams 2002, Yeh and Coggins 2014). This paper emphasizes the active role played by local communities, who translate these global narratives strategically, to develop a critical investigation of the construction and implications of eNGO narratives. The paper aims to provide an understanding of the context of CBNRM adoption in rural China, and to examine how Chinese environmentalism and the meaning of CBNRM are shaped and influenced by global discourses and local interests and interpretations.

\section{ENVIRONMENTAL AND DEVELOPMENT NARRATIVES}

A narrative is a story providing an overarching framework for interpreting or understanding events. Narratives are not neutral but constructed from selective information convenient to fulfil the objectives of the narrators (Blaikie et al. 2007), hence producing a certain version of environmental knowledge and social order (Forsyth and Walker (2008). Much scholarship 
has focused on the construction and implications of environmental narratives (e.g. Blaikie et al. (2007); Fairhead and Leach (1995); Hajer (1995), Walker (2004); Yeh (2009); Yeh and Coggins 2014). Some authors [e.g. Forsyth and Walker (2008); Sturgeon and Menzies (2006); Walker (2001)] specifically address the interactions between ethnicity and narrative construction, explored further below.

Strategically constructed narratives can serve the purpose of advocating and legitimizing CBNRM. One rationale for advocating CBNRM is that since community members share common interests, ideally they should be mobilized to act collectively to participate in NRM. However the formation of a community involves a struggle 'over resources... meaning and identity' (Li T. M. 2001:158) with a community, like a place, 'constructed out of a particular constellation of relations' (Massey 1991:28). Consequently, images and identities of communities and their members are constantly challenged and perceived as socially and politically constructed. Since narratives are constructed to serve certain purposes, they can be misleading and developed from misinterpretations, selectivity and bias. Moreover as 'narratives are dynamic and constantly changing' (Blaikie et al. 2007), it is important to understand the temporal context of a particular narrative. This paper does not intend to focus on the 'truth' of particular narratives, but rather aims to discuss their consequences and implications.

Narratives may be the political strategies of different actors (Li T. M. 1996; 1999) whether of states, to emphasize the responsibility of local communities, or local people, seeking to access opportunities and advance their claims (Li T. M. 1996; 1999; 2002; Tsing 1999). Simplified and generalized images of community have been employed to open up space for 
policy shifts, despite the fact that the representations of the community do not accurately reflect the nature of the community ( $\mathrm{Li} \mathrm{T}$. M. 1999). This is particularly important in this analysis of the narratives of Chinese ethnic minority communities who have been largely marginalized in a restrictive political environment.

Conservationists often choose certain communities as project sites, supposing that these communities have different practices, motivations or aspirations from the outside world, by being more 'traditional' or environmentally minded. However, such communities may have the same aspirations and interests as others, desiring to engage in neoliberal markets rather than in indigenous economic practices, and projects may fail, because of such misunderstandings (Li T. M. 2001; Sturgeon 2007). The differences between how communities are represented and represent themselves and their practices and interests are examined below in the context of CBNRM in Yunnan.

\section{PARTICIPATORY WATERSHED MANAGEMENT IN YUNNAN}

This paper examines a participatory watershed management program in Lashi Lake watershed, close to Lijiang city in Yunnan, where a domestic eNGO, Green Watershed (GW), implemented CBNRM projects in several villages of two ethnic groups, Yi and Naxi, to address multiple natural resource use issues.GW, established in 2000 by a well-known environmentalist, $\mathrm{Yu}$ Xiaogang (hereafter referred to as $\mathrm{Yu}$ ), has been a pioneer of the globally-promoted participatory natural resource management (NRM) approach in China. NRM issues in the Lashi watershed are broadly similar to those in other upland Chinese watersheds. The case study exemplifies the construction of environmental and development 
narratives by an eNGO, the implications of particular narratives and their strategic translation by local communities.

Between 2010 and 2012, one of the authors (Wang) conducted ethnographic fieldwork for nine months in two Lashi villages: Shan village of the Yi ethnic group and Hubin village of the Naxi ethnic group, where GW implemented its project (See Figure 1). The village names are pseudonyms. Participant observation was conducted of village life, alongside informal conversations and formal interviews with local Lashi leaders, government officials of various departments and staff of several eNGOs. In addition, oral histories of local elders documented by GW, GW's project documents and printed government materials were consulted.

(Insert Figure 1 here)

Lashi Lake has been identified as a biodiversity hotspot and many international conservation organizations have worked there, including The Nature Conservancy (TNC). Lashi is predominantly populated by two ethnic minority groups: the Naxi, accounting for $94 \%$ of the population, and the $\mathrm{Yi}$, in the upper catchment of Lashi Lake, who represent another 4\%.

When full, Lashi Lake has an area of approximately 1,000 hectares amongst mountains ranging from 2,440 to 3,840 metres above sea level. The region has wet and dry seasons and, before 1994, the lake flooded and drained annually. In the dry season, the lakebed became fertile land for farming. For lakeside Naxi villages, agricultural production was diverse, including wheat, barley and various fruits. Fishing was a casual seasonal activity. Animal raising was also important since the wetland provided good pasture. Upland Yi villagers 
mainly depended on hunting and animal herding as their main production activities, with some cash income from logging. Farming and non-timber forest product (NTFP) collection also provided livelihoods needs, .

In order to supply water to Lijiang, which had become a popular tourism destination, the Lashi dam was initiated in 1994 and completed in 1998 when the lake's regular flood-dry cycle completely ended. A vast area of land was submerged permanently, and villagers who lost their farmland and pasture had to seek alternatives for their survival, such as logging, fishing, hunting birds and harvesting aquatic plants.

Other events subsequently made livelihoods more difficult for local villagers. In 1999, the Natural Forest Protection Program, NFPP (tianran lin baohu gongcheng) was declared and farming on sloping land was banned as a result of the Sloping Land Conversion Program (SLCP, tuigeng huanlin). Commercial logging wasalso banned and was no longer a viable income source, and many farmers, including both Naxi and Yi, lost their land.

While fishing had been only a casual activity during the wet season, it became an important and even sole income source for many Lashi villagers. Since the early 2000s, increasing demand for fishing led to greater use of illegal fishing gear and greater exploitation of fisheries resources. Consequently, fishery resources decreased dramatically. Meanwhile, due to the loss of lowland farmland, some Naxi villagers started to convert sloping land for potato and corn farming, despite this being prohibited, a process that resulted in soil erosion, chemical runoff and frequent flooding and mudslides, problems identified by local villagers In the mountains, Yi villagers suffered from forest degradation due to the encroachment of state logging concessions from 1950 to the early 1990s, and poverty resulted from a lack of 
cash incomes and viable livelihoods.

In an attempt to address resource issues in Lashi, GW set up a participatory watershed management program (Lashi program)with the support of an international donor, Oxfam (Wang and Connell 2016). Although GW is mostly known for its anti-dam campaign on the $\mathrm{Nu}$ River (Matsuzawa, 2012), its long-term effort has centred on participatory watershed management in China. Like many Chinese eNGOs, GW mainly depended on international funding sources, at least before 2012, with more than $90 \%$ of its budget coming from international donors, such as Oxfam, the World Bank and the Swedish International Development Cooperation Agency.

By analyzing two CBNRM projects under the overall Lashi program, this paper illustrates how eNGOs construct indigenous and community narratives around the relationship between nature and rural Chinese society, how these narratives are consequently adopted or modified by local communities, and the reasons behind the modification. The first case study of Shan village investigates the making of an indigenous narrative, while the second case study in Hubin village looks at the community narrative.

\section{Constructing an indigenous narrative: Forest protection and community development project in an upland Yi village}

Shan village, the most remote of the eight upland Yi villages within Lashi and 3100 metres above sea level, is where GW implemented its forest protection and community development project. Like other Yi villages, it possesses limited resources due to the topography, accentuated by farming and logging bans since 1999. 
Yi ancestors first migrated to this area about a century ago. Before the communist era, the current village land belonged to the He clan in the downstream Naxi community. The Naxi landlord permitted the Liu clan of Yi to stay, as they agreed to serve as guards against invasion. Oral history suggests that the dense forest and lush pasture provided good livelihoods at the time of early settlement, through hunting and animal herding. Bears, deer, monkeys and pheasants were common game. Farming buckwheat, oats and potatoes and harvesting NTFPs such as medicinal plants, honey, mushrooms and pine nuts, provided important sources of nutrition, health and income generation.

The villagers have witnessed significant degradation of the natural environment due to largescale state logging from the 1950 s to the early 1980 s, and commercial logging from the 1980 s until the end of the century. During the 1980s and 1990s, the timber was an important source of local government revenue, and many Naxi were hired for logging. The ecosystem changed quickly and every Yi generation, both male and female can relate their experiences of deforestation, declining NTFP availability and fewer animals for hunting. Elders observed that many animals either froze or starved, due to a lack of forest for shelter and moss for food. Fewer pine nuts were available for harvest because of the lack of large pine trees. Due to environmental degradation, the land was no longer fertile; the only crop was potatoes which had a low market value. The logging ban in 1999 resulted in a significant loss of cash incomes and thus more difficult livelihoods. The main cash income subsequently came from compensation through the SLCP scheme, as people were forced to abandon farming on slopes. In 2011, Shan households received approximately 3,000 RMB (US\$375) each. 
Witnessing these resource degradation and livelihood difficulties, GW initiated in 2002 its CBNRM-based livelihood development and conservation project in the Yi villages, with the focus on Shan village. The objective was to protect the upland forest for the benefit of the entire watershed (Green Watershed 2011; n.d.). The watershed model also fitted into the agenda of Oxfam Mekong Initiative, its main donor, which had sought to engage upstream communities of the Mekong River as partners in its overall program (Ounsted 2003; 2004). GW considered that poverty alleviation and livelihood development would be crucial for effective environmental protection. Natural resources were considered as capital for developing alternative livelihoods. The project encompassed infrastructure, livelihood security, awareness education, and capacity building. A new institution, the village's Watershed Management Committee, representing different family groups, was set up to facilitate project activities. It discussed village rules for resource use, which were modifications of traditional customary uses of the forest. In the past, Yi villagers specified certain areas as ancestral spirit forest in which some practices were forbidden ( $\mathrm{Yu}$ 2004). Current village rules, forbidding logging of all living trees, also prohibit hunting, and access to firewood in areas prone to mudslides. Over the years, the project significantly improved the villagers' life. For example, women were empowered through education which enabled them to work in nearby villages because of the basic language and maths skills acquired Villagers were also exposed to a variety of agricultural opportunities and new crops. Overall, the villagers appreciated the project and the support of GW.

Relocate or stay? eNGO's narratives of 'locality, integrity and authenticity' 
In 2011, the Shan villagers were potentially facing relocation due to the interests of a Naxi businessman, Mr. H, in developing the area for tourism. Although relocation was never enforced, the plan excited discussion within the community, and between GW and the villagers, highlighting the making of a particular narrative by GW.

Before 2011, Mr. H had developed part of the surrounding area by paving the road and planting trees, in the process resettling two other Yi villages. However, the quality of the houses was poor, resettled households were allocated insufficient land for farming and many were forced to seek paid employment to earn their livelihoods. In 2011, the Lashi township officials revealed that Shan village was designated for relocation in its five-year master plan, because it was in a geological hazard zone, and asserted that no funds would be granted to develop the village. At that time, no official survey had been published, no villager consulted and no relocation plan officially announced. Villagers suspected that Mr. $\mathrm{H}$ was behind the proposed plan.

GW opposed the relocation plan, believing that villagers would be better off developing their livelihoods locally rather than attempting to negotiate a better relocation package. During two visits to Shan village in 2011, GW's Director, Yu, discussed the advantages and disadvantages of relocation with the villagers. Villagers expressed various concerns over relocation, mainly derived from the experiences of previously resettled Yi villagers. Some were negative, such as that resettled Yi were given lower priority in obtaining water for irrigation and had to abandon crops sensitive to water shortages. By contrast some saw benefits in better education for their children. During the meetings, Yu emphasized that ecotourism development would bring the same benefits to the villagers as those they would 
receive if they relocated. Yu also stated that since Shan village land was heritage from their ancestors, the villagers were responsible for protecting the forest. This emphasis on 'staying local' and 'protecting ancestor's land' was repeated in almost every meeting between GW and Shan villagers.

GW's action in resisting the relocation reflected its understanding and framing of the Yi human-nature relationship: Shan villagers, perceived as the forest guardians inheriting the land from their ancestors, should protect the forest for the benefit of the entire watershed. GW thus constructed an indigenous narrative emphasizing the 'authenticity, locality and integrity' of the villagers, which portrayed the Yi people as the legitimized traditional users of the forest.

This narrative was communicated both internally, within the Yi villages, and externally, in GW's project documents, where Yi villagers are portrayed as the legitimate users who have protected the environment but had been marginalized both by state policy and the Naxi community. According to one project document: 'The villagers have been depending on the forest for generations since their ancestors ...After the logging ban and SLCP in 1999, Yi people lost their farmland in order to protect the natural forest' (Green Watershed 2008: 15, emphasis added). Yu (2004) also detailed the conflict between Naxi and Yi over forest ownership as the '[S]truggle of Yi against Naxi encroachment'. In an international conference, $\mathrm{Yu}$ (2012) presented the Yi village project as involving 'traditional communitybased natural resource management' with 'social capital including common natural resources, recognizing the ecosystem inherited from the ancestors, based on culture, belief and inner motivations...' 
Likewise Oxfam supported GW's proposal that 'upstream guardians of water resources [the Yi community] should be compensated' (Ounsted 2004). GW, by adopting the indigenous narrative theme, thus legitimized the Yi village's territorial claim (as owners of the land) and cultural claim (as guardians of nature). GW insisted that villagers should resist potential relocation, as protecting the forest was both a legitimate right and a responsibility. However, although this particular narrative proved problematic and oversimplified for several reasons (see below), the language was nevertheless adopted by Shan villagers to strengthen their position. Thus, despite the images of community being misleading, their representation was used by local communities as a political tool to achieve their agendas, a situation similar to that Tania Li (1996) observed in Indonesia. Repeating GW's narrative, stressing villager's cultural and territorial positions, enabled them to negotiate with external interventions, demonstrated in their bargaining with $\mathrm{Mr} \mathrm{H}$ over relocation.

Firstly, although GW constantly stressed the territorial claim of Shan village, the Liu clan was not the traditional owner of the land as their ancestors had migrated about a century earlier. The villagers nonetheless largely embraced the territorial claims imparted by GW and adopted the narrative language. As one local elder said:

If we want to protect Lashi lake, we have to protect the mountain of Lashi first... Only if the mountain survives, so will the water... The Yi upstream of Lashi lake have the responsibility of protecting the forest belonging to the Liu's ancestors. After GW's programe we Yi have successfully protected the forest 
The narrative thus became more legitimate and more powerful as a territorial claim from local elders.

Secondly, GW often represented Shan village as an integrated homogeneous community, while emphasizing the heterogeneity of the Naxi community. Yu (2012) categorized Shan village as a 'traditional' community sharing values of culture and nature, while the Naxi were becoming 'modern' (xiandaide) in focusing on economic benefits and profit. This division was simplistic, as social differences existed between Shan village families, albeit barely visible to outsiders (including GW staff). Thus, while the majority of villagers were willing to consider relocation, if given satisfactory compensation, one $r$ family group, with superior economic and social status, rejected relocation. One family member indicated:

We don't want to move. Here we have freedom to grow whatever we like. We have land and water...Those who want to move are lazy. It takes a lot of effort to farm rapeseed. That is why we grow so much and other families don't.

The family could also negotiate better prices from livestock trading because they were fluent in Mandarin, while limited language ability prevented others from even investing in livestock. Despite this difference, Shan villagers epitomized unity and did not express their desire for relocation in front of GW staff. The image of an integrated community was purposely constructed. As a minority in the Lashi area, being united provided better opportunities and strength when interacting with outsiders, and in gaining trust and support from GW. Thirdly, through the GW project, villagers actively embraced a different type of Yi culture in order to strengthen their cultural authenticity. In the course of a study trip arranged by GW to another 
Yi village of a different lineage which had been successful in tourism operations, Shan villagers bought some Yi utensils, learned a Yi welcoming ceremony and used these when hosting tourists, a form of strategic inauthenticity.

Adopting GW's narrative thus transformed the identity of Shan village as forest guardians, linked to local culture and nature, further strengthening its position as the legitimate resource users in negotiating with external interventions, whether state projects or private developments. Although the Yi community was threatened with relocation, they used this threat as an opportunity to negotiate for their own agenda. For example, Shan villagers requested $\mathrm{Mr}$. $\mathrm{H}$ to improve the road as a pre-requirement for developing the area for tourism. These aspirations were barely known to GW, who insisted that the Shan villagers stay and protect the environment. Shan villagers thus selectively adopted the language of GW to argue for quite different outcomes.

\section{Implications of the indigenous narrative}

GW's constructed narrative supported its CBNRM approach in favour of local people maintaining local livelihoods with the community-protected forest. This narrative both risked ignoring development possibilities not accommodated by CBNRM, and overlooked ongoing illegal practices (mainly logging) by Shan villagers.

Firstly, GW strongly encouraged Shan villagers to stay, rather than relocate, for environmental protection and development, partly because the CBNRM approach favoured resource management by communities rather than the government (or the private sector). However, imposing this responsibility on villagers excluded other development possibilities, 
although the degraded environment no longer offered the possibilities it previously did in a village where average household income was RMB 5000-8200 (US\$ 600-1000) in 2011, which mainly came from compensation payments from SLCP. This potentially created a 'rhetorical poverty trap' tying local communities into a commitment to protecting the forest (Fisher and Hirsch 2008), whereas the majority of villagers preferred relocation to participate in a more urbanized, and perhaps affluent, lifestyle regardless of any narrative relevant to their ethnicity.

Secondly, the indigenous narrative's simplification of complex human-nature interactions ignores problematic resource use. Some Shan villagers were involved in various kinds of illegal hunting and logging activities. Some cut down living trees in the area prohibited by village rules for their own use; others joined relatives outside the Lashi basin, in illegal commercial logging. Certain villagers were involved in transportation of illegal timber across several counties. Although villagers had adopted the language of GW, emphasizing their responsibility as traditional owners to protect the forest, they did not fully internalize the narrative.

Thus GW, based on their CBNRM approach, constructed a stereotyped narrative depicting a united Yi village as guardians of the forest responsible for protecting ancestral land. This indigenous narrative was not only relevant to environmental issues, but had wider political and social implications and implied actions and behaviour that the villagers supposedly exhibited. GW's narrative, while empowering the local community by strengthening its legitimacy over local resources, also disempowered villagers by restricting their development opportunities, while simultaneously providing a narrative from which they could bargain. 


\section{Making a community narrative: an agro-forestry project in a Naxi village}

The second case study considers an agro-forestry project in a Naxi village, Hubin, which GW implemented to address soil erosion problems. Hubin stretches along a valley north-west of Lashi Lake. Houses are built on its slopes. During the 1950s, the area was heavily logged to supply charcoal to the government and soil occasionally washed down into the lake. Soil degradation worsened after the Lashi dam project. After 1996, villagers started to convert the hillsides for corn and potato cultivation, which became illegal after the 1999 ban on sloping land farming. To gain permission for farming, the villagers negotiated with the township government, which eventually permitted every household to cultivate one $m u(\sim 0.67$ hectare). Between 1996 and 2000, approximately $120 \mathrm{mu}$ of sloping land was farmed, increasing runoff, containing chemical fertilizer, into the lake. In heavy rain, many houses were flooded, and mudslides damaged houses, farmland and fields of neighbouring villages. Ironically, despite the conversion of their land, villagers scarcely benefited because of low corn and potato prices.

Aware of the emerging environmental problems, GW initiated a micro-watershed management project which emphasized community participation, arguing that community members could benefit through participating in designing, implementing, monitoring and evaluating project activities ( $\mathrm{Yu}$ 2012). GW hosted a two-day participatory workshop attended by most Hubin households who identified problems of soil erosion, mudslide and poverty. Villagers also faced the issue of depleted fishery resources, as did other Lashi villagers. During the 2000s, numerous activities were undertaken, including watercourse management and agro-forestry. Cultural activities, including organizing Naxi singing and 
dancing, were also considered by GW to preserve and revive traditional Naxi culture, and mobilize the village as a community, while traditional Naxi conceptualizations of naturehuman relationships were also seen by GW as an important project component ( $\mathrm{Yu}$ 2012). Like other CBNRM projects, GW set up several community organizations in the form of village-level committees to mobilize the community, facilitate project activities and build the capacity of community members to address environmental issues collectively.

The agro-forestry project, whose objective was to protect eroding soil and provide alternative livelihoods, significantly transformed household economic and social lives. Income from agricultural activities became the major revenue source for many Hubin villagers. The focus was on replacing corn and potato cropping with fruit trees that were considered to better retain the soil. Although Hubin villagers had grown many fruit tree species locally, including plums, apples and pears, they were mostly for self-consumption and had never been grown for commercial sale prior to the GW intervention.

The agro-forestry project was initiated by four pioneering households. GW provided them with seedlings and a stipend for planting trees. After their initial success, increasing numbers of villagers invested their time, effort and capital in agro-forestry. Over twenty varieties of pears alone are now grown in Hubin. Some people, who had earlier migrated for urban employment, returned to agriculture because of the profits generated.

Prior to the GW project, households earned around 2,000 RMB (US\$290) per year from agricultural activity, whereas households generated income ranging from 5,000 RMB (US\$730) to over 20,000 RMB from fruit farming in early 2010s. Some households opted not 
to practice commercial fruit farming, mainly due to labour shortages. Others, that were not dependent on incomes from fruit, still maintained small plantations, because high-quality fruit made valuable gifts. In 2009, snow peaches from Hubin were supplied for the state banquet in Beijing celebrating the sixtieth anniversary of the People's Republic of China. Fruit trees gradually became both materially and symbolically important.

Hubin villagers became empowered through various activities. They actively adopted new crop varieties and agricultural technology, and gained knowledge through GW workshops and by exchanging information with relatives or friends outside Lashi. Some farmers, famous for their agricultural skills, were hired by people from other parts of Lijiang for pruning. Beyond agricultural activities, villagers cooperated on village affairs, including maintenance and construction of infrastructure, with very little funding from the township government. Some started horse-trekking or restaurant businesses with the profits from fruit sales.

Throughout the project, GW encouraged villagers to protect natural resources as a community. GW staff regularly repeated the phrase 'to protect natural resources collectively' (jiti baohu ziran ziyuan). Villagers were also advised to form a farmer's co-operative for collective fruit marketing and a fishery association to protect their fishery resources. However the success of the GW project did not mean that the villagers fully internalized the community narrative. Villagers were reluctant to join either organization. Meanwhile environmental outcomes became compromised, as villagers continued to convert slopes for farming, and used more agro-chemicals. Thus, although GW stressed the community 
narrative in its CBNRM project, the local 'community' modified, ignored or rejected parts of that narrative.

\section{Compromised Outcome 1-Collective Fruit Marketing}

After the success of agro-forestry, in $2009 \mathrm{GW}$ assisted the villagers to set up a farmers' cooperative, to enable households to benefit from collective fruit marketing. In China, cooperatives have been promoted both by state policy and by many NGOs as a way to mediate the risks of the volatile market to farmers and provide resilience in an increasingly neoliberal economy. While about half the Hubin households joined the co-op, its activities were very limited and no collective fruit marketing was undertaken.

The main reason for the limited role of the co-op was that the type of fruit sales operating in Hubin for several years was arranged by Mr. A, the local leader of GW's project, rather than being coordinated collectively. Every autumn, since 2004, through Mr. A, many households sold pears directly to a businessman from the neighbouring prefecture. This guaranteed villagers a good price, saved time and effort in selling individually to markets in Lijiangbut thisoverlapped and competed with the co-op. Sales arranged by Mr. A differed from the cooperative effort, and concerns existed over the manner of trading. Price negotiation was not transparent and, although Mr. A claimed that he provided his services freely, he charged commission. and also determined which households he would allow to deal with businessmen, thus acting as a middleman rather than a leader of a co-op. Individual agency thus played an important role in shaping eNGOs' project outcomes. Rather than simply following the norms expected of a local leader of NGO projects, Mr. A actively transformed the way GW's 
project was carried out, translating the project activity to his own advantage, so compromising GW's goal of cooperative effort.

\section{Compromised Outcome 2: Environmental Practice}

Another challenge to GW's project, and to the CBNRM, was the compromised environmental outcome. Despite soil erosion being alleviated by the agro-forestry project, villagers continued to convert more sloping land to agriculture and used agro-chemicals, acting against environmental principles by favouring short-term profit over potential long-term ecological and economic benefits, a familiar trade-off between conservation and development.

Hubin fruit was always introduced to visitors as organic. A picture showing a villager and a beautiful peach was often used in printed material implying the success of agro-forestry and organic farming. However, farming practices were not organic. Hubin farmers, like other Lashi villagers, used chemical fertilizers for commercial crops (but not those for selfconsumption). People also used various pesticides, including Bestox, a poisonous product harmful to aquatic species, and occasionally used ripening agents on peaches, so that they would be mature in time to be marketed during the Chinese Mid-Autumn festival when prices were good.

Some Hubin households converted additional areas of sloping land into fruit farming, despite it being prohibited. Such illegal actions were reported to the Natural Forest Protection Office, and fruit trees were felled, but this failed to deter new plantings. Success in agro-forestry project eventually led to compromised environmental outcomes.[] Hubin villagers' increasing use of chemicals and expansion of farming on sloping land maximized short-term benefits, in 
response to uncertain regimes of environmental governance, privatization of natural resources, insecure land tenure and socio-economic injustices resulting from various government projects.

In Lashi, government policies and projects had threatened the livelihoods of the poor. Initially, the Hubin villagers used sloping land because extensive tracts of land were submerged due to the Lashi dam, a project developed without public consultation. Since the sloping land was one of the few resources left to villagers, they needed to maximize its use. Moreover using it was also a way of performing resistance to hegemonic control over their natural resources: a form of silent but active protest. Villagers around Lashi Lake also undertook other illegal environmental practices, such as poisoning waterfowl, as resistance and protest against the unfair government policy [See Hathaway (2013) for the conflicts due to the conservation policy for migratory waterfowl]. The environment became a space of power contestation, while the experience of socio-economic injustices contributed to the modification, or rejection, of the community narrative constructed by the GW project.

Privatization of natural resources also resulted in socio-economic disparities. In Lijiang, this was particularly evident, as rural people witnessed how state power contributed to business profits from the privatization of land and water, and tourism development, which had made Lijiang, and the surrounding area, a hot spot for real estate development. In the early $2000 \mathrm{~s}$, a lakeside wetland five kilometres from Lijiang became the development site for a golf course. Farmers protested over the loss of land, fierce physical conflict occurred and two people died, but the project continued. After the golf course was built, the lake was no longer suitable for 
fishing, the traditional livelihood of people living nearby, due to the heavy use and run-off of pesticides. The lake had effectively been privatized.

The Lashi villagers were also threatened by potential involuntary resettlement from the nearby Jingsha River, where several hydropower stations were financed by private companies backed by the government. Lashi villagers witnessed how private investors benefited from the privatization of hydro-power, while the proposed resettlement posed a significant problem for Lashi villagers, if displaced people were relocated onto already scarce Lashi land resources.

Land tenure insecurity further contributed to shaping decisions prioritizing short-term revenue over long-term benefits. That insecurity surrounding land ownership has both a spatial context, and a historical context, related to the evolution of land-use planning of the region and the country. Several waves of land tenure reform have occurred in China since 1949. Although ultimate ownership belongs to the state, land use rights differed under different regimes. Following decollectivization in the 1980s, land use rights were allocated to village committees and contracted to individual households, but many factors impeded secure land tenure, including the state's natural resource policy, restricting land use, and compulsory land grabbing in the name of public use (Li J. D. P. 2003). Tenure insecurity consequently influenced rural villagers' environmental practices. Many Lashi farmers were reluctant to undertake long-term care of the forest and other land due to their lack of any sense of security. Hubin villagers experienced loss of farmland due to the Lashi Dam, and witnessed how people in the nearby wetland and Jingsha River areas lost their land without proper 
consultation and compensation. They also experienced the threat of resettlement from other areas, and the possible expansion of the Lashi Dam (so submerging more farmland), underpinning the uncertainty that drove them to maximize profits from sloping land farming. Short-term profit from fruit farming was strategically more important than potential longterm benefits.

The experience of Hubin demonstrates how eNGO projects can be compromised, due to the different agendas espoused by eNGOs and local communities. The exercise of local agency is shaped by socio-economic disparities as a result of environmental injustice and uneven development, ubiquitous phenomena in rural China (Webber 2012). Hubin farmers prioritized short-term economic profits, significantly modifying the GW project, resulting in unpredicted outcomes and compromised agendas that diverged from those of GW itself.

\section{Construction and adoption of environmental narratives}

While indigenous and community narratives have emerged in recent years and have been widely adopted by eNGOs in China to implement local projects, the narrative themes that sustain the CBNRM model promoted by eNGOs, may not be readily accepted at village level. The simplicity and lack of economic relevance of particular narratives used to legitimize NGO projects, has meant that implementing CBNRM has encountered difficulties.

Environmental narratives are convenient for those who generate them (Forsyth and Walker 2008), but mask the complex interactions between different actors, the environment and the political economy, at various scales. The various environmental narratives constructed around 
Lashi Lake exemplify how nature-society interactions are deliberately constructed by eNGOs, and how these narratives are actively adopted or modified by the subjects of the narratives.

The Naxi have been depicted as 'living in harmony with nature', both by Naxi scholars and by eNGOs (Li B. 2006; Li L.-F. 2004; Mu 2011). The Nature Conservancy, an international eNGO, which started its China program from the Lijiang region, portrays the Naxi as having ecologically-sound traditions (Hathaway 2013). By contrast, the Yi are often understood by the public as the enemies of nature due to slash and burn practices, and as a 'backward' ethnic group. In a document of one domestic eNGO discussing ethnic groups in Lijiang that have harmonious relationships with nature, the Yi are excluded since only the Naxi and Tibetans are regarded as ethnic groups respecting nature (Li B. 2006). None of these simplified stories of the Naxi and Yi reflect reality.

Naxi customary rules for natural resource use are however no longer practiced, rarely known by ordinary Naxi, and even perceived by many as superstitious following the Cultural Revolution. Moreover, farming and logging practice of Naxi and Yi in the past did not differ much. Naxi also used to practice slash and burn agriculture (Yin 2008), a practice that was deemed destructive in the mainstreamed peasant narrative. Nowadays, Naxi use of natural resources differs little from that of farmers and fishers elsewhere in rural China. The Naxi in the Lashi area harvest fish intensively with fishing technology introduced from other provinces, and convert sloping land for agriculture, in the face of similar challenges, including land expropriation and consolidation, competitive markets and rising prices. This 
has involved diversifying livelihoods, lowering production costs and intensifying agricultural practices.

In contrast to the mainstream narrative, $\mathrm{GW}$, by emphasizing the $\mathrm{Yi}$ as the guardians of the forest, has constructed a very different narrative regarding ethnicity and the relationship to the environment. Through revealing the history of Naxi encroachment on the Yi's forest, GW attempted to shift the blame for destroying the forest away from the Yi, to strengthen the position of the marginalized Yi within the Lashi area.

Environmental narratives frequently link ethnicity and resource use patterns. In the case of land use by ethnic groups in Northern Thailand, Forsyth and Walker (2008) argue that stereotyping of ethnic groups by outsiders (including eNGOs) offers a simplified explanation of nature-human interactions, based on certain ideologies and strategic purposes, with advocates using what Li refers to as 'strategic simplifications' to argue for the rights of local communities (Li T. M. 2002:265). Local people are crucial to legitimizing this narrative, evident where Yi villagers actively adopted part of the environmental narrative, maintaining their image as the legitimate resource users. The credibility of the constructed GW narratives is contingent on their reception by the villagers, whether positive or negative. The power of narratives is effectively granted to the NGOs by the villagers. Without the cooperation and conviction of the people in the 'story', the constructed narrative cannot be legitimized and sustained. This case study demonstrates that local villagers have been very much involved in developing and rejecting eNGO narratives, rather than depending on Chinese elites, including academics and activists, as narrators (Hathaway 2010; 2013). 


\section{Indigeneity and community narrative themes in China}

While both indigenous and community narrative themes have been championed by eNGOs in China, it remains challenging for eNGOs to advocate these narrative themes as they may not be readily embraced by rural people. Neither indigenous nor community narratives, are fully internalized by local communities, even though they are specifically designed to be relevant. As the development of and reaction to the projects indicates, the community narrative theme was unable to mobilize Naxi villagers into participating in CBNRM. Likewise, even though the Yi villagers partially adopted the narrative of indigeneity, their actions did not comply with eNGO ideology. Promoting and implementing the CBNRM approach based on either narrative themehas proved a difficult task. Different landscapes, diverse cultures, state disregard and uneven policy implementation all have an effect.

Two additional reasons exist why rural Chinese have been reluctant to embrace community and indigenous narrative themes advocating collective resource management, either as a community or as an indigenous group. Firstly, there has been ambiguity over the terms 'community' and 'collective', due to the incompatibility of a western sense of 'community' with that in a Chinese context. Because 'collective' has negative connotations stemming from recent Chinese history, villagers are reluctant to manage natural resources collectively. Contemporary privatization trends have also rendered the term 'collective' old-fashioned, unprofitable, and unattractive. Secondly, the eNGO's envisioning of resource management lacks an essential cultural and territorial basis for constructing and representing an indigenous group. 


\section{Managing resources as a community and as a collective unit}

The term 'community' has multiple connotations. No Chinese word is compatible with the English term 'community'. Although "community" is used by most eNGOs (especially the larger international agencies) in China, it is unfamiliar to rural people, hence it is at best an ambiguous concept. A compatible translation of the term in the context of resource management is "she qu"; direct translation offers "social district/block", a translation that captures its spatial characteristics, and more familiar urban usage. The Chinese term for a non-spatial community is "she qun", meaning 'social group'. No single Chinese term conveys the diverse meaning of community, despite the term being widely used in the context of CBNRM.

While eNGO staff and local leaders use the term 'community' when associating with outsiders, neither NGO staff nor villagers use the word locally. Consequently 'working as a community' for managing resources collectively is often abbreviated by eNGOs (including $\mathrm{GW}$ ), when communicating with rural villagers, to 'working collectively' (jiti). However, the concept of collective is incompatible with the concept of community in the CBNRM approach. For rural Chinese people, 'working collectively' does not have the same meaning as 'working as a community', so villagers are often confused over 'managing resources collectively' and 'managing as a collective unit'. Nevertheless, this perspective is often overlooked by NGOs and consequently mis-communicated to villagers. In China, the collective unit, or people's commune, was a bureaucratic body set up by the state for the purposes of economic production and political control during the planned economy era (approximately between 1958 and 1984). Although a collective could be geographically 
based in a village, it was not the same as a community. Nor was it derived from bottom-up peasant movements, but defined by top-down state power (Qing 1998). The different kinds of social capital a community owns, such as trust between members, may not necessarily exist in a collective.

For rural Chinese people, the term 'collective' has negative connotations implying 'going back to the collective period'. Consequently, in Lashi, there was reluctance on the part of the villagers to participate in CBNRM projects, which included economic organizations such as the farmers' co-op. No villagers said they participated in NGO projects because they considered CBNRM worked better. Whenever GW staff told villagers that natural resources should be collectively managed by the community, silence followed: a powerful expression of dissent. Villagers were reluctant to adopt the idea that natural resources should be collectively managed ('community management' in NGO terminology), because the term 'collective' reminded them of a past era when they endured poverty and hunger. Collective management was seen as old fashioned; private ownership was modern, and offered real benefits. The ambiguous meaning of 'collective' and the recent trend towards privatization rendered community-based projects unattractive.

\section{Lack of territorial and cultural claims}

As a community or an indigenous group is constructed, lack of territorial and cultural claims can weaken both the making and sustaining of such groups. In the case of the Naxi villages, the process of community-building, or indigeneity-building, was absent, because the villagers were either reluctant or unable to make cultural or territorial claims. The lack of territorial 
claims mainly resulted from land tenure insecurity, while the lack of cultural claims was due to the dismantling of the traditional culture, hastened by the Cultural Revolution. The Naxi case studies thus differ from earlier cases where peasants and indigenous people based their claims on their traditional culture or ownership of land [e.g. Li T. M. (1996); Tsing (1999)]. While Naxi have been widely perceived as an ethnic minority group living in harmony with nature, the Naxi themselves make very few claims to managing their natural resources as either a community or as an indigenous group.

Naxi villagers have been reluctant to associate with Dongba, the traditional system of religion that encompasses the wisdom of nature, Naxi culture, and Naxi script. Dongba is considered a 'backwards' belief by many Naxi, hence cultural claims are weak in terms of the social construction of the community in Lashi. The ideology of the human-nature relationship in Dongba is no longer valued or practiced by ordinary Naxi. Again, this was mainly due to the Cultural Revolution, during which Dongba was labelled 'superstitious', literature was destroyed, priests were executed, and schools demolished. In line with subsequent government policy however, the culture has been widely used for cultural consumption by Lijiang's tourism industry, despite Dongba rarely having any connection with people's everyday lives. In general, Naxi in Lashi are reluctant to be considered 'traditional' thus there is no motivation for them to reclaim their culture. It is common for both Naxi and Yi to desire modern urban lifestyles, much like other ethnic minorities, such as the Akha, who show more interest in 'being rich than being green' (Sturgeon 2007:150).

The Naxi are unenthusiastic about voicing their territorial claims, mainly due to land tenure insecurity discussed earlier. People have witnessed both the weakness of land claims and 
recent land-grabbing, hence territorial claims have had a very limited effect on making and sustaining indigenous groups.

The situation of Yi village was somewhat different. The Yi villagers partly adopted the indigenous narrative, emphasizing their cultural and territorial claims over natural resources, because of their scarce development opportunities compared to the Naxi. When faced with limited choices, they were more likely to claim and take any available resources, including eNGO narratives which could be used to strengthen their position. In addition, since GW maintained a relatively good relationship with the villagers, the latter were more inclined to adopt GW's agenda. This kind of NGO-community alliance can benefit local communities: constituting a form of social capital (Austin and Eder 2007). Nevertheless, the indigenous narrative may not suit the interests of all groups deemed 'indigenous' by outsiders.

\section{Conclusion}

Quite legitimately eNGOs have sought to preserve indigenous identities and promote community-based conservation. Constructing indigenous or community narratives in line with international discourses enables support and funding. Narratives can also be utilized to achieve political and/or conservation outcomes, by claiming and championing indigenous/community rights over natural resources (Li T. M. 2002; Walker 2001). Yet both indigenous or community narrative themes face challenges in terms of adoption. As these cases show, different narrative themes work out differently according to the local context, a context that can vary even within a small geographical area such as the Lashi watershed. As a fixed model will rarely fit into any community in which the environment, economy and 
socio-cultural context are constantly changing, there is a risk for eNGOs promoting any narrative with homogeneous characteristics and expecting people to internalize it into their practice.

CBNRM projects in China encounter difficulties that are distinct from other countries, partly due to the recent political and economic history of China, which is in itself fluid and complex, in terms of the state's vision of ecological modernization, and its multi-scalar consequences. CBNRM, an ever-changing approach modified and improved by practitioners globally, offers a pathway to environmental governance with potential benefits for local communities, but whose effectiveness and credibility is contingent on its relationship with social-economic structures. Environmental change is inherently a contested social and political process. More research thus needs to be done in addressing the conflicts and tensions involved in establishing bottom-up and participatory institutions for natural resource governance in rural China.

Acknowledgements

We would like to thank the two anonymous and insightful referees, the villagers of Hubin and Shan, and the staff of Green Watershed.

\section{References}

Austin, R. \& Eder, J. (2007). Environmentalism, development, and participation on Palawan Island, Philippines. Society \& Natural Resources, 20(3):14. 
Blaikie, P., Springate-Baginski, O., Banerjee, A., Bhatta, B., Saigal, S., \& Sarin, M. (2007). Actors and their narratives in participatory forest management. In O. SpringateBaginski \& P. Blaikie (Eds.), Forest, people and power: The polical ecology of reform in South Asia. London: Earthscan,pp.1-23.

Dressler, W., Büscher, B., Schoon, M., Brockington, D., Hayes, T., Kull, C., et al. (2010). From hope to crisis and back again? A critical history of the global CBNRM narrative. Environmental Conservation, 37(01):5-15.

Fairhead, J., \& Leach, M. (1995). False forest history, complicit social analysis: Rethinking some West African environmental narratives. World Development, 23(6):1023-1035.

Fisher, R. \& Hirsch, P. (2008). Poverty and agrarian-forest interactions in Thailand. Geographical Research, 46(1):74-84.

Forsyth, T., \& Walker, A. (2008). Forest guardians, forest destroyers: The politics of environmental knowledge in northern Thailand. Seattle: University of Washington Press.

Green Watershed. (2008). laizi Lashihai liuyu de baogao (A report from Lashi Lake Watershed). Kunming: Green Watershed.

Green Watershed. (2011). 2011 nian yizu shequ fazhan xiangmu nianzhongzongjie (Final report of Yi community development project in 2011). Unpublished document.

Green Watershed. (n.d.). Yi livelihood and sustainable development project. Retrieved 9 November 2013, from website: http://www.greenwatershed.org/news-363-11714.html

Hajer, M. (1995). The politics of environmental discourse: Ecological modernization and the policy process. Oxford: Clarendon Press. 
Hathaway, M. (2010). The emergence of indigeneity: Public intellectuals and an indigenous space in southwest China. Cultural Anthropology, 25(2):301-333.

Hathaway, M. (2013). Environmental winds: Making the global in southwest China. Oakland: University of California Press.

Li, B. (2006). Analysis of threats to wetland conservation and local livelihoods in NW Yunnan, China. Kathmandu: International Centre for Integrated Mountain Development.

Li, J. (2003). Rural land tenure reforms in China: Issues, regulations and prospects for additional reform. Seattle: Rural Development Institute.

Li, L.-F. (2004). Value of Dongba culture in the view of humanity. Journal of Yunnan Normal University, 36(5):17-23.

Li, T.M.(1996). Images of community: Discourse and strategy in property relations. Development and Change, 27(3):501-527.

Li, T. M. (1999). Compromising power: Development, culture, and rule in Indonesia. Cultural Anthropology, 14(3):295-322.

Li, T. M. (2001). Boundary work: Community, market and state reconsidered. In A. Agrawal \& C. Gibson (Eds.), Communities and the environment: Ethnicity, gender and the state in community-based conservation. New Brunswick: Rutgers University Press. pp. 157-179.

Li, T. M. (2002). Engaging simplifications: Community-based resource management, market processes and state agendas in upland Southeast Asia. World Development, 30(2):265283.

This article is protected by copyright. All rights reserved. 
Litzinger, R. (2004). The mobilization of 'Nature': Perspectives from north-west Yunnan. China Quarterly (178):488-504

Massey, D. (1991). A global sense of place. Marxism Today (June): 24-29.

Matsuzawa, S (2012) Citizen Environmental Activism in China: Legitimacy, Alliances and Rights-based Discourses, ASIANetwork Exchange, 19(2), 81-91.

Mu, L. (Ed.). (2011). Naxi shui wenhua (The Naxi's water culture). Kunming: Yunnan Science and Technology Press.

Ounsted, M. (2003). Oxfam, serendipity, and the Mekong: A team leader's reflection on the lessons to be learned from the development of Oxfam American's East Asia Regional Program and the Oxfam Mekong Initiative. Boston: Oxfam America.

Ounsted, M. (2004). Evaluation of Oxfam America's grants $C N$ 05/02 and CN 008/03. "Poverty Alleviation and Community-based Watershed Management in Lashi Township, Lijiang" for the period June 2002- June 2004, with reflections and lessons for the whole pilot project, 2000-2004. Boston: Oxfam America.

Qing, H. (1998). The mystery of the commune: Revisiting the collectivization of agriculture. Twenty-First Century Bimonthly, 48:22-33.

Sturgeon, J. (2007). Pathways of "indigenous knowledge" in Yunnan, China. Alternatives, $32: 129-153$

Sturgeon, J.\& Menzies, N. (2006). Ideological landscapes: Rubber in Xishuanbanna, Yunnan, 1950 to 2007. Asian Geographer, 25(1-2):21-37.

This article is protected by copyright. All rights reserved. 
Tsing, A. L. (1999). Becoming a tribal elder, and other green development fantasies. In T. M. Li (Ed.), Transforming the Indonesian uplands: Marginality, power and production. Amsterdam: Hardwood.pp. 159-202.

Tsing, A. L., Brosius, P., \& Zerner, C. (2001). Introduction: Rasing questions about communities and conservation. In A. Tsing, P. Brosius \& C. Zerner (Eds.), Communities and conservation: Histories and politics of community-based natural resource management. Walnut Creek: Altamira. pp. 1-34.

Walker, A. (2001). The 'Karen consensus', ethnic politics and resource-use legitimacy in northern Thailand. Asian Ethnicity, 2(2):145-162.

Walker, A. (2004). Seeing farmers for the trees: Community forestry and the arborealisation of agriculture in northern Thailand. Asia Pacific Viewpoint, 45(3):311-324.

Wang, J. Z. \& Connell, J. (2016). Green Watershed in Yunnan: A multi-scalar analysis of environmental non-governmental organisation (eNGO) relationships in China. Australian Geographer, 47(2):215-232.

Webber, M (2012). Making capitalism in rural China. Cheltenham: Edward Elgar.

Western, D., \& Wright, M. (1994). The background to community-based conservation. In D. Western \& M. Wright (Eds.), Natural connections: Perspectives in community-based conservation . Washington D.C.: Island Press. pp.1-12.

Williams, D (2002) Beyond Great Walls. Environment, Identity and Development on the Chinese Grasslands of Inner Mongolia, Stanford: Stanford University Press.

Yeh, E. (2009). From wasteland to wetland? Nature and nation in China's Tibet. Environmental History, 14(1):103-137.

This article is protected by copyright. All rights reserved. 
Yeh, E. and Coggins, C (2014) Mapping Shangri-La: Contested Landscapes in the SinoTibetan Borderlands, Seattle: University of washington Press.

Yin, S. (2008). The mountain fire faded away:Swidden agriculture in anthropological perspective. Kunming: Yunnan People's Publishing House.

$\mathrm{Yu}, \mathrm{X}$. (2004). Conflict in resource management of ecosystem services: Water in the Lashi Watershed, Lijiang,Yunnnan, China. In D. Nathan, G. Kelkar \& P. Walter (Eds.), Globalization and indigenous peoples in Asia: Changing the local-global interface. New Delhi: Sage, pp.119-140.

Yu, X. (2012). Natural resource exploitation, sustainable development and the rights of Yi nationality in mountain areas: Case study in Lashihai area. Paper presented at the Natural Resource Exploitation, Environment and Minority Culture in Economic Development, Oslo. 


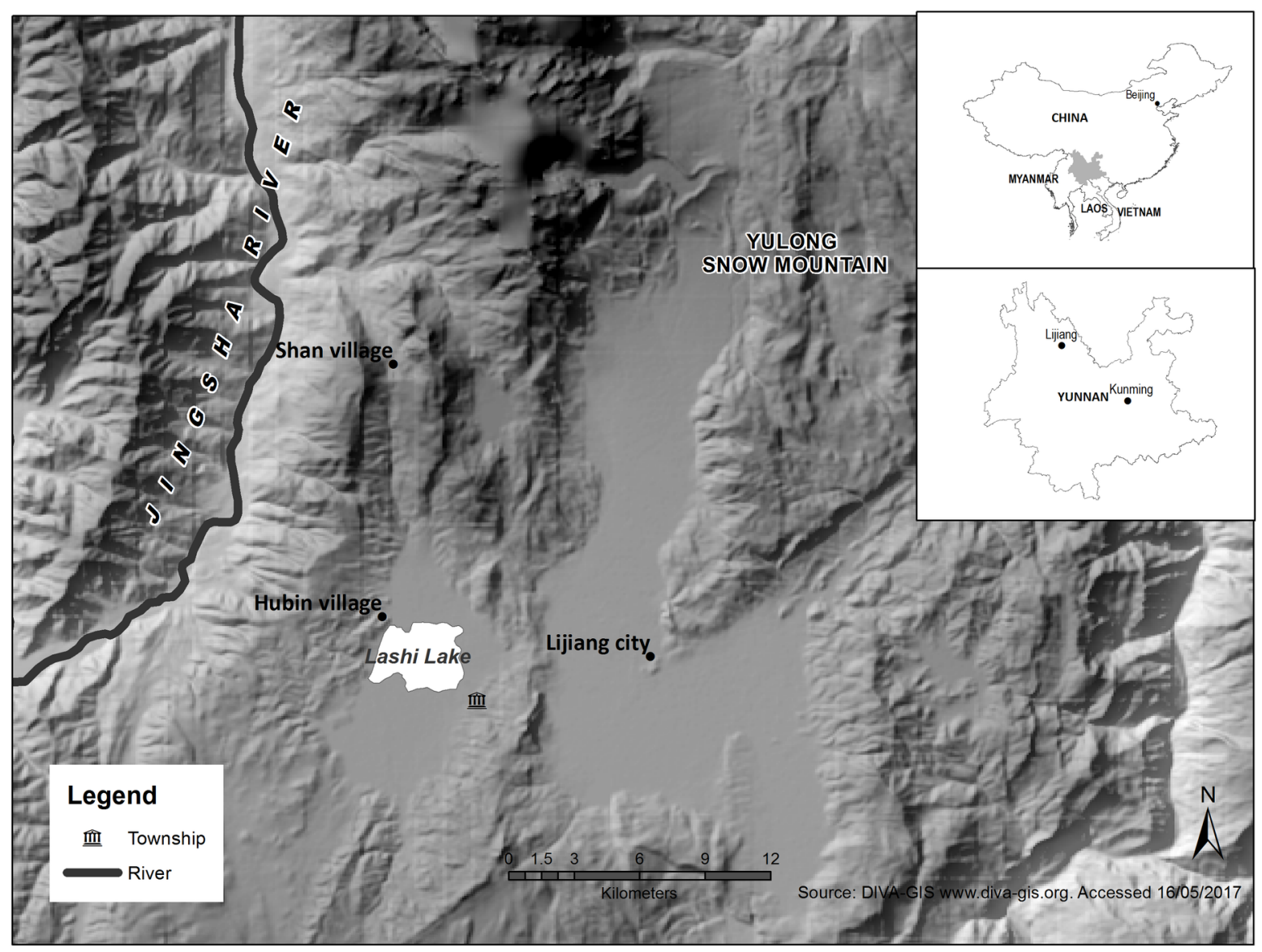

Map1.tif

This article is protected by copyright. All rights reserved. 


\section{Participatory Natural Resource Management in Rural China: Making and Unmaking Environmental Narratives}

Ju-Han Zoe Wang*1, Robert Fisher ${ }^{2,3}$ John Connell ${ }^{2}$

1. Asia Institute, University of Melbourne.

2. School of Geosciences, University of Sydney.

3. Tropical Forests and People Research Centre, University of Sunshine Coast.

*Corresponding author:

Asia Institute, Sidney Myer Asia Centre, The University of Melbourne, Victoria 3010 Australia

Email: zoe.wang@unimelb.edu.au 


\section{University Library}

\section{- M M N E R VA A gateway to Melbourne's research publications}

Minerva Access is the Institutional Repository of The University of Melbourne

Author/s:

Wang, JHZ;Fisher, R;Connell, J

Title:

Participatory natural resource management in rural China: Making and unmaking environmental narratives

Date:

2018-01-01

Citation:

Wang, J. H. Z., Fisher, R. \& Connell, J. (2018). Participatory natural resource management in rural China: Making and unmaking environmental narratives. Asia Pacific Viewpoint, 60 (2), pp.205-219. https://doi.org/10.1111/apv.12210.

Persistent Link:

http://hdl.handle.net/11343/284781 